\title{
Improved the Agrobacterium tumefaciens-mediated transformation of cucumber by a modified the using of antibiotics and acetosyringone
}

\section{Li'ang Chai}

Zhejiang $A$ and $F$ University

Changxia Du ( $\nabla$ changxiadu@zafu.edu.cn )

https://orcid.org/0000-0002-0366-2224

Huaifu Fan

Zhejiang $A$ and $F$ University

Chen Liu

Zhejiang $A$ and $F$ University

Yuyang Si

Zhejiang A and F University

\section{Research}

Keywords: Cucumber, Agrobacterium , Kanamycin, Bacteriostatic antibiotics, Acetosyringone, Genetic transformation

Posted Date: June 2nd, 2020

DOl: https://doi.org/10.21203/rs.3.rs-31968/v1

License: (c) (i) This work is licensed under a Creative Commons Attribution 4.0 International License. Read Full License 


\section{Improved the Agrobacterium tumefaciens-mediated}

\section{2 transformation of cucumber by a modified the using of}

3 antibiotics and acetosyringone

4 Li'ang Chai ${ }^{1}$, Changxia Du, ${ }^{1,2}$, Huaifu Fan², Chen Liu, Yuyang Si

5 Zhejiang Provincial Key Laboratory of Agricultural Product Quality Improvement Technology, College of Agriculture and Food

6 Science, Zhejiang A\&F University, Hangzhou 311300, Zhejiang, P. R. China.

7 Li'ang Chai: LyonChai@Outlook.com

8 Changxia Du: changxiadu@zafu.edu.cn

$9 \quad$ Huaifu Fan: wwghff@126.com

10 Chen Liu: 903141747@qq.com

11 Yuyang Si: thisyy@Outlook.com

12 : $:$ Co-first authors; ${ }^{2}$ : Corresponding author

13 Abstract

Background: Cucumber (Cucumis sativus) is one of the most important vegetable crops in the world. As conventional breeding of cucumber is very challenging, genetic engineering is an alternative option to introduce important traits such as enhanced stress resistance and nutritional value. However, the efficiency of the transformation system depends on genotypes, transformation conditions, selection agents, etc. This study aims to speed up the process of Agrobacterium-mediated transformation of cucumber. 'Xintai mici, a very popular and typical north China-type cucumber variety, was transformed with

21 Agrobacterium GV3101. The strain carried pCAMBIA2300s plasmid, a double vector with 22 the marker gene of neomycin phosphotransferase II (npt II).

Results: The research results indicated that cefotaxime sodium was suitable for inhibiting 
Agrobacterium in the stage of screening and bud elongation. Timentin was best used during rooting stage. Furthermore, $25 \mathrm{mg} / \mathrm{L}$ kanamycin was used in the early stage of screening and increased to $50 \mathrm{mg} / \mathrm{L}$ for further screening. At the bud elongation and rooting stage, 75 and $100 \mathrm{mg} / \mathrm{L}$ kanamycin was used respectively to improve the screening efficiency. In order to obtain the highest regeneration frequency of resistant buds, 50, 150, and $100 \mu \mathrm{M}$ acetosyringone were added in the pre-culture medium, infection solution, and co-culture medium respectively. To confirm the presence of the transgenes, DNA from npt II transgenic cucumber plants was analyzed by polymerase chain reaction after transplanting resistant regenerated plants.

Conclusions: We finally achieved an $8.1 \%$ conversion, which was among the highest values reported until date using cucumber 'Xintai mici'. Thus an effective protocol for Agrobacterium tumefaciens-mediated genetic transformation of cucumber was optimized.

Keywords: Cucumber, Agrobacterium, Kanamycin, Bacteriostatic antibiotics, Acetosyringone, Genetic transformation

\section{Background}

Cucumber (Cucumis sativus) is one of the most important vegetable crops widely grown in the world. The studies on gene function and genetic breeding of cucumber have been concerned world widely[1,2]. Abnormal expressions of genes in transgenic cucumber plants can help us to engineer and select more robust crop species, such as resistance to biotic and abiotic stress, fruit quality improvement[3], growth and development $[4,5]$. Since the advent of cucumber tissue 
culture and genetic transformation technology $[6,7]$, researchers have made a lot of achievements in the transformation of genes through improvement and optimization of transformation methods. In present, Agrobacterium tumefaciens-mediated transformation system of cucumber is still one of the most mature and popular genetic transformation methods[8]. However, the genetic transformation efficiency of cucumber is still low. The key factors affecting the infection efficiency of Agrobacterium include the type of explant[9], Agrobacterium species[10], exogenous hormone[11, 12], selection agent[13], Agrobacterium inhibitors[14] and phenols[15], etc. In addition, the cutting ways of explants[16] and the mode of infection, such as vacuum infiltration treatment $[13,15]$, also have an impacts on the transformation of cucumber in varying degrees.

In the selective culture stage of cucumber genetic transformation, selection antibiotics and antimicrobial antibiotics are often used together[17]. Kanamycin, hygromycin and glyphosate are used for selection markers commonly[13]. It is generally believed that the resistance of cucumber explants to selection antibiotics is closely related to its genotype and culture stages. Instead, antibiotics that have little effect on explants and certain inhibition effect on Agrobacterium are often selected and used[17, 18], such as cefotaxime sodium, carbenicillin, and timentin[15]. However, they are often used at a high concentration, which also have a certain impacts on the regeneration and growth of explants[19]. Many studies found that phenolic had a significant effect on the regeneration frequency of resistant buds, which was added to the pre-culture, infection and co-culture stages of genetic transformation[15, 20]. It is widely recognized that the phenolic, such as acetosyringone, can activate the vir gene of Agrobacterium and promote the introduction of 
foreign genes into the plant genome, and then the efficiency of genetic transformation is improved[21]. However, acetosyringone is often dissolved in toxic organic solvents or has toxic effects in high concentrations and interacts with infection modes and other transform conditions[22]. Therefore, the specific addition stages and concentrations of acetosyringone were different in the existing reports[1].

The unconformity between the infection site of Agrobacterium and the regeneration site of explants is the most important reason for the low efficiency of the genetic transformation of cucumber. And the inconsistent sites are affected by various conditions and factors[1,23]. Besides, the selection and the concentration of antibiotics are the main factors affecting the regeneration of positive buds[14]. However, these parameters were different in various literatures and also lack of enough details in the existing studies. All of these reasons leaded to browning, Agrobacterium pollution, vitrification shoots, low efficiency of genetic transformation[24], gene expression and genetic instability, which still perplex researchers. In order to improve the efficiency of genetic transformation, the effects of different concentrations of kanamycin on the regeneration of cotyledonary nodes by applying it in different transformation periods were analyzed in the present study. Meanwhile the inhibitory effects of three different antibiotics on Agrobacterium and the effects on regenerated buds were evaluated, and the effects of acetosyringone on the regeneration frequency of resistant buds in different stages of cucumber genetic transformation were researched.

This study hopes to provide a reference for the future researches of cucumber transgenic. 


\title{
Results
}

\section{Effects of kanamycin on regeneration frequency and browning of explants}

\author{
The untransformed explants were placed in the mediums with different kanamycin
} concentrations for $28 \mathrm{~d}$ (Fig. 1-a). The regeneration frequency of buds and browning level showed an opposite trend with the increase of kanamycin concentration. The regeneration frequency of 0 $\mathrm{mg} / \mathrm{L}$ treatment was $90.0 \%$ and significantly higher than that of any other treatments. The prominent differences were observed between 25,75 , and $100 \mathrm{mg} / \mathrm{L}$ treatments. However, the regeneration frequencies of 50,75, and $100 \mathrm{mg} / \mathrm{L}$ treatments was not notable difference. Browning began to appear at $50 \mathrm{mg} / \mathrm{L}$ treatment and reached the peak at $100 \mathrm{mg} / \mathrm{L}$ treatment $(90.0 \%)$. Except for $100 \mathrm{mg} / \mathrm{L}$ treatment, there was no obvious difference among other treatments (Fig. 1-b).

\section{Effects of bacteriostatic antibiotics on Agrobacterium and explants}

The explants were cultured in the selective medium containing $300 \mathrm{mg} / \mathrm{L}$ of cefotaxime sodium, carbenicillin, and timentin respectively for $28 \mathrm{~d}$ (Fig. 2-a). The experiment identified that $300 \mathrm{mg} / \mathrm{L}$ of the three antibiotics could inhibit the growth of the Agrobacterium on the explants. Cefotaxime sodium treatment had the highest resistant buds frequency $(76.7 \%)$ and shared the same level of difference with timentin treatment. The lowest resistant buds frequency $(43.3 \%)$ came from carbenicillin treatment and had no significant difference with timentin treatment (Fig. 2-b). The part c of Fig. 2 showed the growth of Agrobacterium on different types of antibiotics. When the culture time researched $96 \mathrm{~h}$, the highest diameter of inhibition zone was in timentin treatment $(6.4 \mathrm{~cm})$. On the contrary, carbenicillin treatment was the lowest $(5.6 \mathrm{~cm})$. Significant 
104 the maximum diameter of inhibition zone $(5.8 \mathrm{~cm})$ in response to the timentin treatment was

105 observed. And the result was similar with timentin and cefotaxime sodium treatments. However,

106 the diameter of inhibition zone of carbenicillin treatment decreased significantly and reached to

107 the lowest level $(4.4 \mathrm{~cm})$ over time (Fig. 2-d). In another experiment, uninfected explants were

108 cultured with different concentrations of cefotaxime for $28 \mathrm{~d}$ (Fig. 2-e). With the increase of

109 cefotaxime sodium concentration, the number of regenerated buds in each explant decreased from

1107.1 to 2.7 , which almost reduced 4 times. Compared with $0 \mathrm{mg} / \mathrm{L}$ treatment, the $100 \mathrm{mg} / \mathrm{L}$

111 treatment was not significantly altered the numbers of regeneration buds. The number of

112 regeneration buds of 0 and $100 \mathrm{mg} / \mathrm{L}$ treatments were significantly higher than that of any other

113 treatments. There was no significant difference among 200, 300 and $400 \mathrm{mg} / \mathrm{L}$ treatments (Fig.

$1142-f)$.

115 Effects of acetosyringone on regeneration of resistant buds

116 Different concentrations of acetosyringone were added respectively to four important stages

117 of genetic transformation respectively, the pre-cultivation (Fig. 3-a), infection (Fig. 3-b),

118 co-cultivation (Fig. 3-c), and selective culture stages (Fig. 3-d). The regeneration frequencies of

119 resistant buds were counted respectively after $28 \mathrm{~d}$ and shown as follows.

In the test of adding acetosyringone in the pre-cultivation stage, the frequency of resistant

121 buds increased initially and then decreased with the raise of acetosyringone concentration. $50 \mu \mathrm{M}$ 
than that of 100,200 , and $400 \mu \mathrm{M}$ treatments. Whereas, acetosyringone greater than or equal to $100 \mu \mathrm{M}$ showed severe inhibition to the frequency of resistant buds. There was no notable difference between 0 and $50 \mu \mathrm{M}$ treatments (Fig. 3-e). As shown in Fig. 3-f, the final frequency of resistant buds increased first and then decreased with the raise of acetosyringone concentration in the process of Agrobacterium inoculum. The regeneration frequency of resistant buds reached the peak (53.3\%) under $150 \mu \mathrm{M}$ treatment, which was significantly lowe than $200 \mu \mathrm{M}$ treatment (20.0\%). Besides $150 \mu \mathrm{M}$ treatment, no significant difference was found between any other treatments. From the Fig. 3-g we could know that the frequency of resistant buds increased first and then decreased with the raise of acetosyringone concentration in the co-cultivation stage. 100 $\mu \mathrm{M}$ treatment had the highest regeneration frequency of resistant buds $(80.0 \%)$, which was at the same level of difference with 50 and $200 \mu \mathrm{M}$ treatments and comparatively significantly higher than that of the 0 and $400 \mu \mathrm{M}$ treatments. The lowest regeneration frequency of resistant buds was in 0 and $400 \mu \mathrm{M}$ treatments (33.3\%), which had no obvious difference compared with 50 and 200 $\mu \mathrm{M}$ treatments. The explants grew in a screening medium with additional acetosyringone, and the $\mu \mathrm{M}$ treatments were sharing another difference level. Taken together, these results suggested that extra acetosyringone could increase the regeneration frequency of resistant buds while in the early stages of transformation, but not after it was been screening (Fig. 3). 
The regenerated plants of cucumber were domesticated. And the total DNA of the ninth tender leaf was extracted. The primers of report gene $n p t$ II were used to identify the transformed plants (Fig. 4-a), and a 480 bp product was amplified, which was the same as the positive control. The primers of the Agrobacterium genome were used to eliminate the contamination of plants from Agrobacterium, and the total DNA of regenerated plants was not amplified except for lane 12, 17, and 18 (Fig. 4-b). DNA of wide-type plant and negative control were not amplified (Fig. 4).

\section{Discussion}

This study was conducted to establish an Agrobacterium tumefaciens-mediated antimicrobial antibiotics by observing the growth of explants and Agrobacterium in different concentrations. The addition amount of acetosyringone was changed when applied to different culture stages. Then the optimized regeneration protocol was adapted to transformation for cucumber.

\section{Effects of kanamycin on explants}

Kanamycin has a great inhibitory effect on untransformed explants, especially the growth of root[25]. Therefore, kanamycin was widely used as a selection marker with successful results[26, the different sensitivity to kanamycin. As shown in Fig. 1, the regeneration of the buds was 
order not to affect the regeneration of the delicate explants, $25 \mathrm{mg} / \mathrm{L}$ kanamycin was used after

164 co-culture and then raised to $50 \mathrm{mg} / \mathrm{L}$ for further screening without browning. In addition, the concentration of kanamycin could be increased to 75 and $100 \mathrm{mg} / \mathrm{L}$ to prevent the emergence of false-positive plants[28] at buds elongation and rooting culture stages. The dynamic concentration of kanamycin $(50-100 \mathrm{mg} / \mathrm{L})$ accorded with the relevant reports[29, 30].

\section{Effects of bacteriostatic antibiotics on Agrobacterium and explants}

Different strains of Agrobacterium had different sensitivities to antibiotics[31]. The specific effect of the antimicrobial antibiotics was not reported in the cucumber transformation. Therefore, it is very important to select the antibiotics which can effectively inhibit the pollution of the Agrobacterium GV3101 and have little effect on cucumber regeneration buds simultaneously. There were significant differences in the effects of three commonly used antimicrobial antibiotics (cefotaxime sodium, carbenicillin, and timentin) on the explants and Agrobacterium. This data demonstrated that the highest regeneration frequency of resistant buds could be obtained by using cefotaxime sodium (Fig. 2-a and b). It might due to the related chemical structures with auxin which could interact with others in the culture medium[32]. Timentin had the best antibacterial effect and the longest duration than others (Fig. 2-c and d) for its highly resistant to $\beta$-lactamases produced by bacteria[33] but was not as cheap and common as cefotaxime sodium in practical use. Besides, we found that the medium containing cefotaxime sodium (Fig. 5-II) would turn yellow gradually within 2 weeks in buds elongation culture stage, which could not be seen in the medium with timentin (Fig. 5-I). It was reported that the yellowing medium containing harmful substances 
was caused by the accumulation of o-quinones through enzymatic browning[34]. On the other hand, the toxic effect of cefotaxime sodium on the shoot rooting had been reported[17]. In this sense, cefotaxime sodium was more suitable for cucumber genetic transformation and could be added in the medium in the selective and buds elongation culture stages, while timentin could be added in rooting culture stage because of its long lasting effect[35]. Besides, carbenicillin was unsuitable for the genetic transformation of cucumber 'Xintai mici'. The effect of cefotaxime sodium on the explants further determined indicated that $100 \mathrm{mg} / \mathrm{L}$ concentration of cefotaxime sodium had little effect on explants, while $500 \mathrm{mg} / \mathrm{L}$ showed significant inhibition (Fig. 2-e and f). The suitable concentration of cefotaxime sodium was $200-400 \mathrm{mg} / \mathrm{L}$, which could be adjusted according to the extent of pollution from Agrobacterium.

\section{Effects of acetosyringone on the regeneration of resistant buds}

Yadav et al. indicated that twelve low molecular weight phenolic compounds and salicylic acid were the main substances secreted after the explants of chick-pea (Cicer arietinum L.) were injured, and polyphenol oxidase was activated to oxidize phenols[34]. These led to the decrease of phenol and the increase of o-quinones gradually with time, which was one of the factors that resulted in the difficulty of T-DNA transport. Also, secretions such as salicylic acid and gallic acid also inhibited the growth and transformation of Agrobacterium. In many studies, the transformation efficiency of cucumber was improved by adding additional phenol, such as acetosyringone[20, 27]. It could also be achieved by inhibiting the oxidation of phenols, like adding antioxidants, such as $\alpha$-Caprylic acid, L-Cystine, dithiothreitol, and $\mathrm{Na}_{2} \mathrm{~S}_{2} \mathrm{O}_{3}$ [34]. The 
study that adding different contents of acetosyringone in four key steps of genetic transformation

204 showed that the content of acetosyringone had a significant effect on the regeneration of resistant mici'.

\section{Conclusions}

In recent years, although new genetic transformation methods had been reported, such as 
cucumber. The Agrobacterium tumefaciens-mediated transformation system of cucumber is still

224 one of the most concerned transformation methods, and the improvement scheme is still the focus.

225 But cucumber is still one of the most difficult species for transformation, although it has been carried out for 39 years[7]. The highest transformation efficiency of cucumber was 26\%[2], while the lowest was only $0.1 \%$, and mostly between $1 \%-10 \%$ [2]. Moreover, there were few reports about the transformation of cucumber 'Xintai mici'[39]. previous reports in cucumber. The complete transformation method was used in the study and the main steps of which were shown in Fig. 5. We increased the infection depth through the vacuum system. And we set a gradient concentration of kanamycin to prevent the damage of tender plants and the emergence of false-positive and chimeric plants. We used three antimicrobial antibiotics in different stages by comparing their effects on the growth of Agrobacterium GV3101 and explants. By changing the usage of acetosyringone in the important genetic transformation stages, we improved the regeneration frequency of resistant buds by increasing the content of phenolics. We successfully obtained the transgenic plants from cotyledonary nodes of cucumber 'Xintai mici' after 3-month of application of the improved genetic transformation system (Fig. 5). From 223 explants, 134 resistant buds were regenerated, and 42 rooting regenerated plants were obtained. At

240 last, 18 plants were identified as positive. The positive rate was $42.8 \%$, and the transgenic 241 efficiency was $8.1 \%$, which had been improved comparing with other reports[39]. This project 242 was undertaken to improve Agrobacterium-mediated transformation of cucumber with similar 


\section{Materials and Methods}

245

\section{Plant materials and media}

The seeds of cucumber 'Xintai mici' (a north China-type cucumber variety) were soaked for $2-3 \mathrm{~h}$ in water, whose seed coat were peeled. The unclad seeds were dipped in $75 \%$ ethanol for 1 min and $15 \%$ sodium hypochlorite for $15 \mathrm{~min}$, then were rinsed 4 times in sterile distilled water.

The sterilized seeds were germinated in the dark at $28^{\circ} \mathrm{C}$ for $48 \mathrm{~h}$ and light for $24 \mathrm{~h}$ with the medium-I (2.21 g/L M519 + $15 \mathrm{~g} / \mathrm{L}$ sucrose $+2.5 \mathrm{~g} / \mathrm{L}$ phytagel, $\mathrm{pH}=6.8)$. Cotyledonary nodes were first cut in half, $2 \mathrm{~mm}$ hypocotyls were retained, the distal 2/3 parts and growth point were removed. Cotyledonary nodes were cultured in the medium-II $(4.43 \mathrm{~g} / \mathrm{L} \mathrm{M} 519+30 \mathrm{~g} / \mathrm{L}$ sucrose + $2.5 \mathrm{~g} / \mathrm{L}$ phytagel $+0.5 \mathrm{mg} / \mathrm{L}$ 6-benzylaminopurine $+1.0 \mathrm{mg} / \mathrm{L}$ abscisic acid + $1.0 \mathrm{mg} / \mathrm{L} \mathrm{AgNO}_{3}$, $\mathrm{pH}=6.8)$ with varying concentrations $(0,50,100,150$, and $200 \mu \mathrm{M})$ of acetosyringone in the dark at $28^{\circ} \mathrm{C}$ for $24 \mathrm{~h}$.

\section{Agrobacterium strain and vector}

The Agrobacterium strain GV3101 was used for transformation. The binary vector was pCAMBIA2300s, including the neomycin phosphotransferase II (npt II) selection marker, driven by the CaMV-35S promoter. The Agrobacterium was resuscitated in Luria-Bertani (LB)-I medium $(5 \mathrm{~g} / \mathrm{L}$ yeast extract $+10 \mathrm{~g} / \mathrm{L}$ tryptone $+10 \mathrm{~g} / \mathrm{L} \mathrm{NaCl}+15 \mathrm{~g} / \mathrm{L}$ agar, $\mathrm{pH}=5.8)$ with $50 \mathrm{mg} / \mathrm{L}$ kanamycin, $25 \mathrm{mg} / \mathrm{L}$ rifampicin at $28^{\circ} \mathrm{C}$ until single colonies appearing. The Agrobacterium single 
colonies were added to $1 \mathrm{~mL}$ of LB II $(5 \mathrm{~g} / \mathrm{L}$ yeast extract $+10 \mathrm{~g} / \mathrm{L}$ tryptone $+10 \mathrm{~g} / \mathrm{L} \mathrm{NaCl}$,

$\mathrm{pH}=5.8$ ) with $50 \mathrm{mg} / \mathrm{L}$ kanamycin, $25 \mathrm{mg} / \mathrm{L}$ rifampicin at $28^{\circ} \mathrm{C}$ until turbid. Then the

Agrobacterium was cultured with $100 \mathrm{~mL}$ of LB II containing $50 \mathrm{mg} / \mathrm{L}$ kanamycin, $25 \mathrm{mg} / \mathrm{L}$

rifampicin at $28^{\circ} \mathrm{C}$ until optical density at $600 \mathrm{~nm}\left(O D_{600}\right)$ of $0.6-0.8$ was achieved. The

Agrobacterium culture was centrifuged and resuspended in the medium-III (2.21 g/L M519 + 15

added to the medium-III. Before inoculation, the resuspended Agrobacterium inoculum was shaken for the induction of vir genes at $28^{\circ} \mathrm{C}$ for $1 \mathrm{~h}$.

\section{Effects of kanamycin and bacteriostatic antibiotics on Agrobacterium and explants}

Varying concentrations of kanamycin $(0,25,50,75$, and $100 \mathrm{mg} / \mathrm{L})$ and cefotaxime sodium $(0$, $\mathrm{mm}$ diameter sterile filter paper with $0.5 \mathrm{mg}$ of bacteriostatic antibiotics (cefotaxime sodium,

278 carbenicillin, and timentin) was placed in the center. Petri dishes were placed in the $28^{\circ} \mathrm{C}$ bacteria incubators for $96 \mathrm{~h}$ and $30 \mathrm{~d}$.

Inoculation, co-cultivation, screening, and regeneration 
breathable filter membranes. Erlenmeyer flasks were placed in a vacuum system, $0.094 \mathrm{MPa}$ for 5 min. The vacuum was relieved slowly to prevent damage to explants caused by stress transients. The infected explants were cultured in the medium-II with a sterile filter paper in the dark at $28^{\circ} \mathrm{C}$ for $48 \mathrm{~h}[40,41]$. Varying concentrations $(0,50,100,200$, and $400 \mu \mathrm{M})$ of acetosyringone were added in the medium-II. After co-cultivation, explants were washed 5 times with sterilized distilled water. Explants were blotted dry on sterile filter paper. Then explants were transferred to the medium-II. $50 \mathrm{mg} / \mathrm{L}$ kanamycin, the varying concentrations of acetosyringone $(0,50,100,200$, and $400 \mu \mathrm{M}$ ) and bacteriostatic antibiotics (cefotaxime sodium, carbenicillin, and timentin, 300 $\mathrm{mg} / \mathrm{L}$ ) were added in the medium-II respectively. Petri dishes were placed in the tissue culture room, $28^{\circ} \mathrm{C}, 4000 \mathrm{Lx}, 16 \mathrm{~h} / \mathrm{d}$. The medium was changed every 2 weeks until 2-cm-high regenerating buds were grown.

Resistant regeneration buds were cut off and transferred to the medium-IV (4.43 g/L M519 + $30 \mathrm{~g} / \mathrm{L}$ sucrose $+2.5 \mathrm{~g} / \mathrm{L}$ phytagel $+0.2 \mathrm{mg} / \mathrm{L}$ 6-benzylaminopurine $+1.0 \mathrm{mg} / \mathrm{L} \mathrm{AgNO}_{3}, \mathrm{pH}=6.8$ ) containing $75 \mathrm{mg} / \mathrm{L}$ kanamycin and $300 \mathrm{mg} / \mathrm{L}$ cefotaxime sodium or timentin to grow for 2 weeks. Then the resistant regeneration buds were transferred to the medium-V $(2.21 \mathrm{~g} / \mathrm{L}$ M519 + $15 \mathrm{~g} / \mathrm{L}$ sucrose $+2.5 \mathrm{~g} / \mathrm{L}$ phytagel $+1.0 \mathrm{mg} / \mathrm{L} \mathrm{AgNO}_{3}, \mathrm{pH}=6.8$ ) containing $100 \mathrm{mg} / \mathrm{L}$ kanamycin and 300 $\mathrm{mg} / \mathrm{L}$ timentin to induce rooting for 2 weeks. The regeneration plants with flourishing roots were transferred into the matrix $\left(V_{\text {Peat }}: V_{\text {Perlite }}=1: 1\right)$ and domesticated in an artificial climate chamber (Day: $28^{\circ} \mathrm{C}, 6000 \mathrm{Lx}, 16 \mathrm{~h}$; Night: $18^{\circ} \mathrm{C}, 8 \mathrm{~h}$; Relative humidity: $65 \%$ )[42]. Each regeneration cucumber was covered with cling film to maintain humidity for 1 week. Then the cucumber plants 
were managed by normal water and fertilizer[43].

\section{DNA isolation and PCR analysis}

Cucumber 'Xintai mici' was genetically modified with the improved genetic transformation

system. After obtaining regenerated plants, the ninth new leaf of the cucumber regeneration plants

was removed, quick frozen with liquid nitrogen, and their total DNA was extracted by CTAB

method[44]. PCR was used to confirm the presence of the transgene in primary transformants.

PCR reactions were carried out in a $20 \mu \mathrm{L}$ volume containing $2 \mu \mathrm{L}$ of $10 \times \mathrm{PCR}$ Buffer, $200 \mu \mathrm{M}$

of each dNTP, $0.4 \mathrm{U}$ rTaq DNA polymerase, $100 \mathrm{ng}$ template DNA, $1 \mu \mathrm{M}$ of each primer. The

primer sequences were $n p t$ II Forward 5'-TCGGCTATGACTGGGCACAACAGA-3' and $n p t$ II

Reserve 5'-AAGAAGGCGATAGAAGGCGATGCCT-3', yielding an amplification product of

480 bp. Excluding the Agrobacterium genome primers were HrcA Forward

5'-TATAATCGACCATCGGTACGATACG-3'[15], yielding an amplification product of $800 \mathrm{bp}$.

\section{Ethics approval and consent to participate}

\section{Consent for publication}

All authors agreed to publish this manuscript. 


\section{Availability of data and materials}

All data generated or analyzed during this study are available in this published article.

\section{Competing interests}

The authors declare that they have no competing interests.

\section{Funding}

This work was financially supported by the Natural Science Foundation of Zhejiang Province of China (LY18C150004, LY18C150003, LY15C150006), and the National Natural Science Foundation of China (31101539 and 31201658).

\section{Authors' contributions}

C. D. and H. F. conceived and designed the study. L. C., C. L., and Y. Y. S. performed the experiments. L. C. wrote the paper with inputs from all authors.

\section{Acknowledgments}

We are grateful for helps from the Zhejiang Provincial Key Laboratory of Agricultural Product Quality Improvement Technology in Zhejiang A\&F University.

\section{References}

[1] $\mathrm{Hu}, \mathrm{B}$, et al. Engineering non-transgenic gynoecious cucumber using an improved transformation protocol and optimized CRISPR/Cas9 system. Mol Plant. 2017; 10(12): $1575-1578$.

[2] Zhang, ZX, et al. A protocol for Agrobacterium-mediated transformation of cucumber 
[3] Yang, L, et al. LITTLELEAF (LL) encodes a WD40 repeat domain-containing protein associated with organ size variation in cucumber. Plant J. 2018; 95(5): 834-847.

[4] Zhao, W, et al. CsTFL1b may regulate the flowering time and inflorescence architecture in cucumber (Cucumis sativus L.). Biochem Bioph Co. 2018; 499(2): 307-313.

[5] Liu, PP, et al. Expression vector construction of Rubisco activase gene CsRCA and genetic

[7] Wehner, TC, Locy, R. In vitro adventitious shoot and root formation of cultivars and lines of Cucumis sativus L. Hort Sci. 1981; 16(6): 759-760.

[8] Jiang, L, et al. Transcriptomic analysis reveals the roles of microtubule-related genes and transcription factors in fruit length regulation in cucumber (Cucumis sativus L.). Sci Rep. $2015 ; 5: 8031$.

[9] Wang, Y, et al. Genetic analysis and identification of a candidate gene associated with in vitro regeneration ability of cucumber. Theor Appl Genet. 2018; 131(12): 2663-2675.

[10] Chetty, VJ, et al. Evaluation of four Agrobacterium tumefaciens strains for the genetic transformation of tomato (Solanum lycoper-sicum L.) cultivar Micro-Tom. Plant Cell Rep. 
361

[11] Wang, W, et al. Cucumber ECERIFERUM1 (CsCER1), which influences the cuticle properties and drought tolerance of cucum-ber, plays a key role in VLC alkanes biosynthesis. Plant Mol Biol. 2015; 87(3): 219-233.

[12] Mohiuddin, AKM, et al. Influence of silver nitrate (ethylene inhibitor) on cucumber in vitro shoot. Plant Cell Tiss Org. 1997; 51: 75-78.

[13] Wang, SL, et al. Current status of genetic transformation technology developed in cucumber (Cucumis sativus L.). J Integr Agr. 2015; 8(12): 469-482.

[14] Kim, HA, et al. Development of transgenic cucumber expressing TPSP gene and morphological alterations. J Plant Bio. 2010; 37(1): 72-76.

[15] Nanasato, Y, et al. Improvement of Agrobacterium-mediated transformation of cucumber (Cucumis sativus L.) by combination of vacuum infiltration and co-cultivation on filter paper wicks. Plant Biotechnol Rep. 2013; 7(3): 267-276.

[16] Prem, AR, Rafael, PT. Improved cucumber transformation by a modified explant dissection and selection protocol. Hort Sci. 2005; 40: 431-435.

[17] Estopà, $M$, et al. Study of different antibiotic combinations for use in the elimination of Agrobacterium with kanamycin selection in carnation. Plant Cell Tiss Org. 2001; 65: $211-220$.

[18] Ogawa, Y, Mii, M. Meropenem and moxalactam: Novel $\beta$-lactam antibiotics for efficient 
[19] Holford, P, Newbury, HJ. The effects of antibiotics and their breakdown products on the in vitro growth of Antirrhinum majus. Plant Cell Rep. 1992; 11: 93-96.

[20] Kose, E, Koç, NK. Agrobacterium-mediated transformation of cucumber (Cucumis Sativus L.) and plant regeneration. Biotechnol Biotec Eq. 2014; 17(2): 56-62.

[22] Yang, $\mathrm{H}$, et al. Establishment of genetic transformation system by Agrobacterium tumefaciens of cucumber. Southwest China J Agric Sci Rep. 2014; 27(4): 1656-1660.

[23] Bhattacharya, A, Sood, P, Citovsky, V. The roles of plant phenolics in defense and communication during Agrobacterium and Rhizobium infection. Mol Plant Pathol. 2010; 11: 705-719.

[24] Sun, YD, et al. Establishment of a high-efficiency genetic transformation system of cucumber (Cucumis sativus) using Csexpansin 10 (CsEXP10) gene. Int J Agric Biol. 2017; 19(03): $545-550$.

[25] Gaba, V, Zelcer, A, Gal-On, A. Cucurbit biotechnology: the importance of virus resistance. In vitro Cell Dev-Pl. 2004; 40: 346-558.

[26] Vasudevan, A, et al. Agrobacterium-mediated transformation in cucumber (Cucumis sativus L.). Cucurbit Genetics Cooperative Report. 25: 14-16. 
[27] Soryu, NT, Hiroyasu, K, Takahiko, HI. Transformation of cucumber (Cucumis sativus L.) plants using Agrobacterium tumefaciens and regeneration from hypocotyl explants. Plant Cell Rep. 1996; 15: 809-814.

[28] Paul, C, Dennis, E, McCabe. Prediction of germ-line transformation events in chimeric Ro transgenic soybean plantlets using tissue-specific expression patterns. Plant J. 1992; 2: $283-$ 290.

[29] Raharjo, SHT, et al. Transformation of pickling cucumber with chi-tinase-encoding genes using Agrobacterium tumefaciens. plant Cell Rep. 1996; 15: 591-596.

[30] Raharjo, SHT, Punja, ZK. Regeneration of plantlets from embryogenic suspension cultures of pickling cucumber (Cucumis Sativus L. CV. Endeavor). In Vitro Cellular \& Developmental Biology - Plant. 1994; 30P: 16-20.

[31] Gelvin, SB. Agrobacterium-mediated plant transformation: the biology behind the 'gene-jockeying' tool. Microbiol Mol Biol Rev. 2003; 67(1): 16-37.

[32] Ling, HQ, Kriseleit, D, Ganal, MW. Effect of ticarcillin/potassium clavulanate on callus growth and shoot regeneration in Agrobacterium-mediated transformation of tomato (Lycopersicon esculentum Mill.). Plant Cell Rep. 1998; 17: 843-847.

[33] Labia, R, Morand, A, Peduzii, J. Timentin and $\beta$-lactamases. J. Antimicrob. Chemother. 1986; 17(Suppl C): 17-26.

[34] Yadav, R, et al. Improvement in Agrobacterium-mediated transformation of chickpea (Cicer arietinum L.) by the inhibition of polyphenolics released during wounding of cotyledonary 
node explants. Protoplasma. 2015; 254(1): 253-269.

419

[35] Cheng, ZM, Schnurr, JA, Kapaun, JA. Timentin as an alternative antibiotic for suppression of Agrobacterium tumefaciens in genetic transformation. Plant Cell Rep. 1998; 17(8): 646-649.

[36] Anjum, NA, et al. Transport phenomena of nanoparticles in plants and animals/humans. Environ Res. 2016; 151: 233-243.

[37] Chandrasekaran, J, et al. Development of broad virus resistance in non-transgenic cucumber using CRISPR/Cas9 technology. Mol Plant Pathol. 2016; 17(7): 1140-1153.

[38] He, ZQ, et al. Mannose selection system used for cucumber transformation. Plant Cell Rep. 2006; 25(9): 953-958.

[39] Wang, J, et al. Agrobacterium-mediated transformation of cucumber (Cucumis sativus L.) using a sense mitogen-activated protein kinase gene (CsNMAPK). Plant Cell Tiss Org. 2013; 113: $269-277$.

[40] Bakshi, S, et al. Agrobacterium-mediated transformation of cowpea via sonication and vacuum infiltration. Plant Cell Rep. 2011; 30: 2281-2292.

[41] de Oliveira, MLP, et al. High-efficiency Agrobacterium-mediated transformation of citrus via sonication and vacuum infiltration. Plant Cell Rep. 2009; 28: 387-395.

[42] Selvaraj, N, et al. In vitro organogenesis and plant formation in cucumber. Biol Plantarum. 2006; 50(1): 123-126.

[43] Li, X, et al. A protocol for Agrobacterium-mediated transformation of cucumber (Cucumis 
sativus L.) from cotyledon explants. Plant Biotechnol J. 2017; 9(6): 405-416.

438 [44] Li, HQ, et al. Genetic transformation of Torenia fournieri using the PMI/mannose selection system. Plant Cell Tiss Org. 2007; 90(1): 103-109. 
Figures

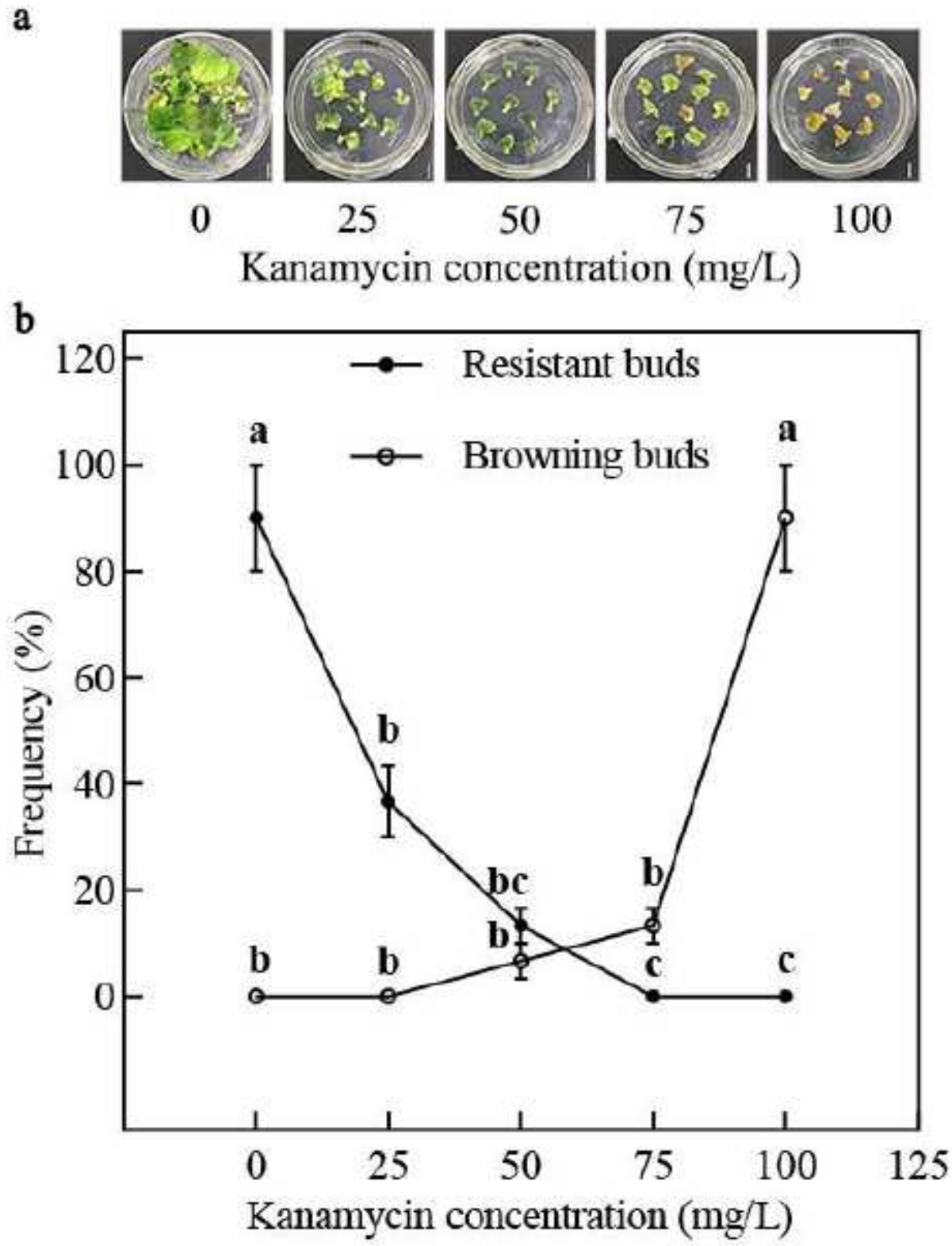

Figure 1

Browning and regeneration frequency of explants at different kanamycin concentrations. a, Growth and browning of explants at different kanamycin concentrations. Bar: $1 \mathrm{~cm}$. b. Analysis of variance of regeneration frequency and browning frequency. Values are means of 3 replicates \pm SE and 10 explants were repeated each time. Different lowercase letters show significant difference at $p<0.05$ by Tukey's test after analysis of variance. 
a

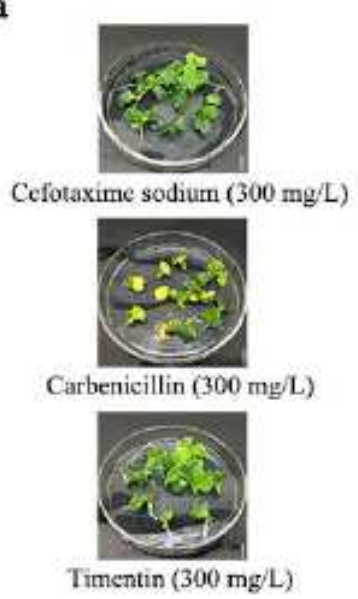

c Bacterial culture time (96 h)

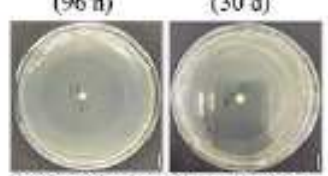

Cefotaxime sodium (0.5 mg)

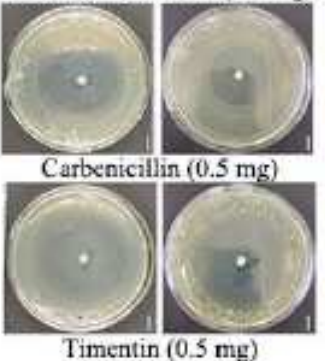

e

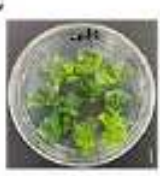

0

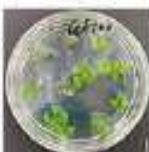

100

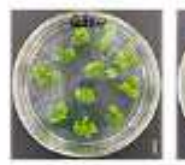

200

Cefotaxime sodium concentration $(\mathrm{mg} / \mathrm{L}$ )
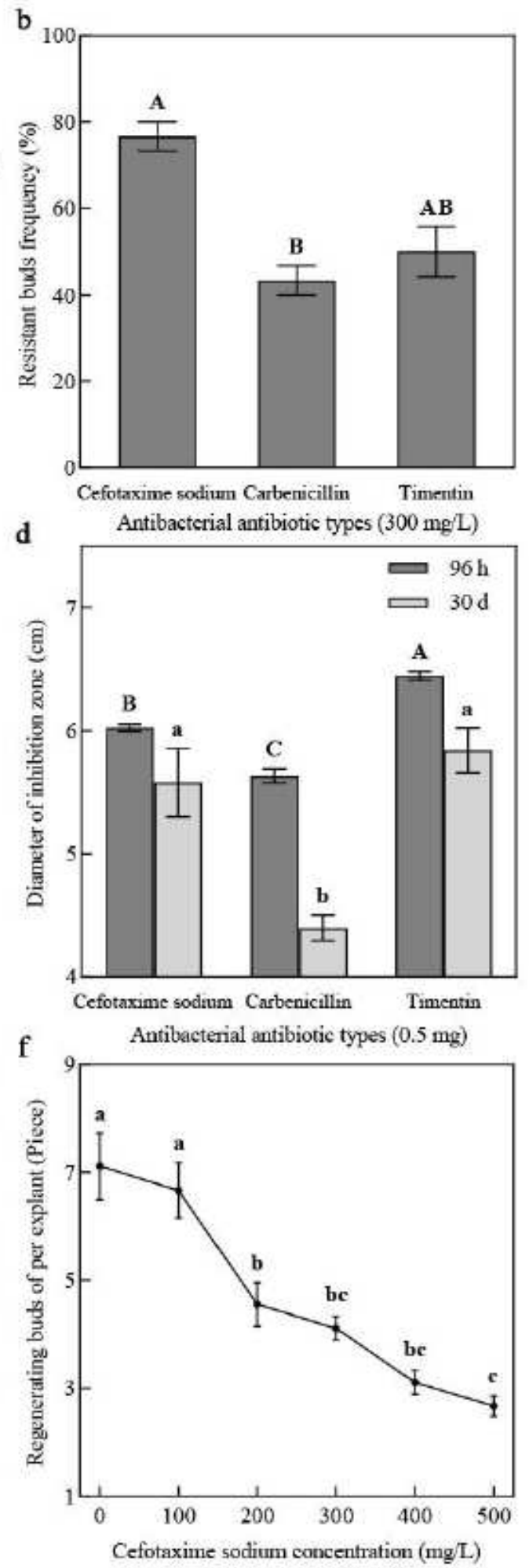

\section{Figure 2}

Effects of bacteriostatic antibiotics on Agrobacterium and explants. a, Growth of explants at $300 \mathrm{mg} / \mathrm{L}$ of different bacteriostatic antibiotics. $b$, Analysis of variance of regeneration frequency at $300 \mathrm{mg} / \mathrm{L}$ of different bacteriostatic antibiotics. c, Inhibitory effect of $0.5 \mathrm{mg}$ of different bacteriostatic antibiotics on Agrobacterium in $96 \mathrm{~h}$ and $30 \mathrm{~d}$. d, Analysis of variance of diameter of inhibition zone in $96 \mathrm{~h}$ and $30 \mathrm{~d}$. e, Regeneration of explants at different concentrations of cefotaxime sodium. Bar: $1 \mathrm{~cm}$. f, Analysis of 
variance of regeneration buds of per explant at different concentrations of cefotaxime sodium. Values are means of 3 replicates \pm SE and 10 explants were repeated each time. Different lowercase letters show significant difference at $p<0.05$ and different capital letters show very significant at $p<0.01$ by Tukey's test after analysis of variance.

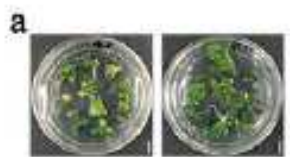

0

$\begin{array}{ccc}50 & 100 & 200 \\ \text { Acetosyringone concentration }(\mu \mathrm{M})\end{array}$

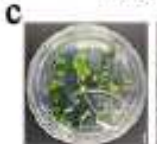

0

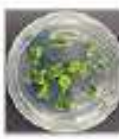

50

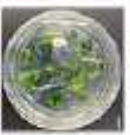

100

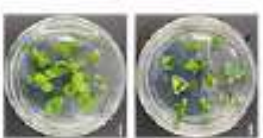

200
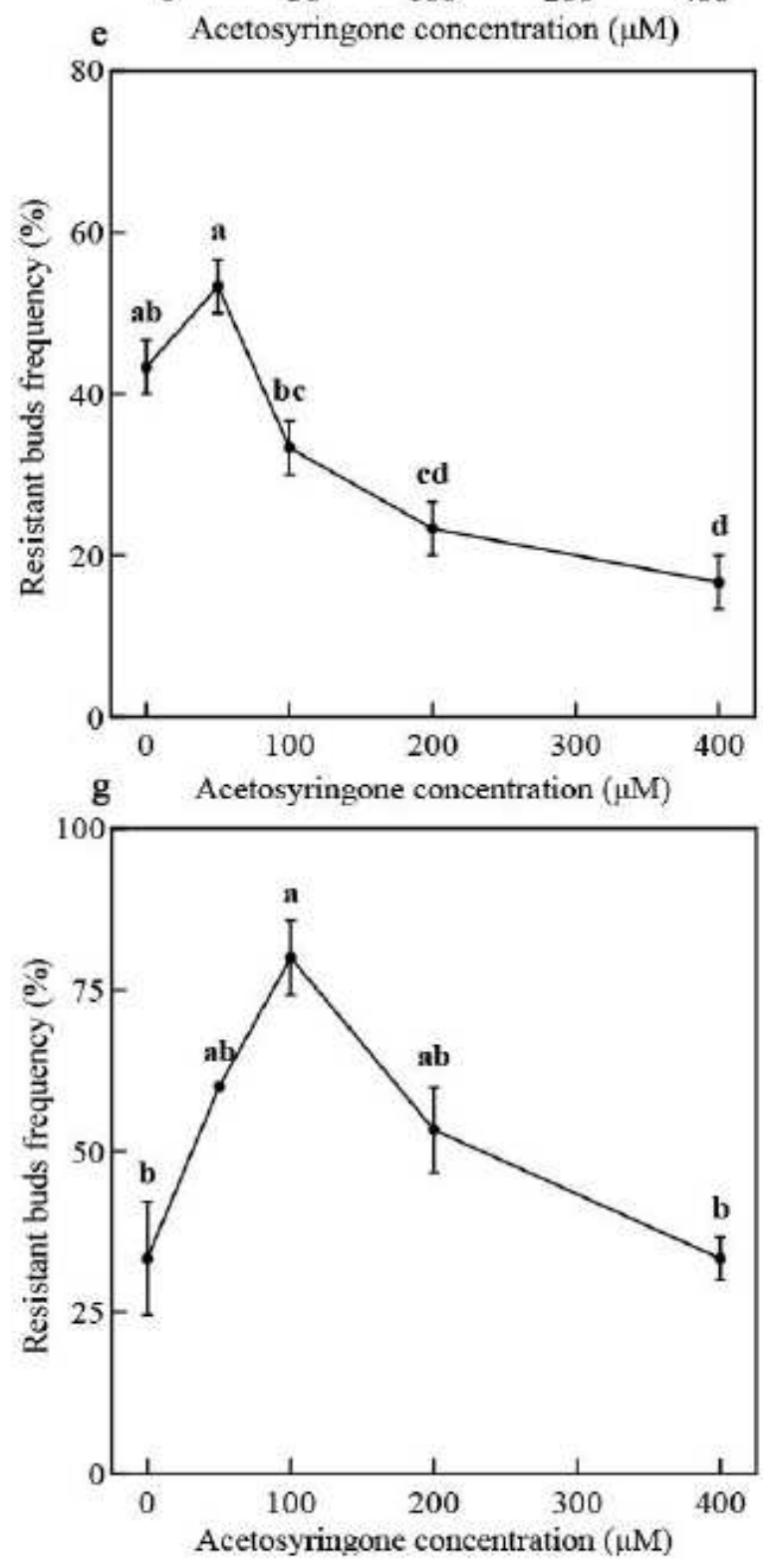

b

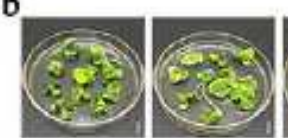

$0 \quad 50$
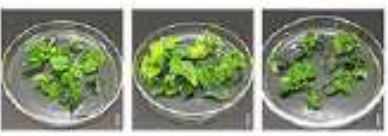

100

150

200

d

Acetosyringone concentration $(\mu \mathrm{M})$

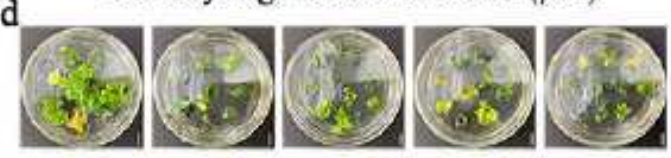

0

50

100

150

200
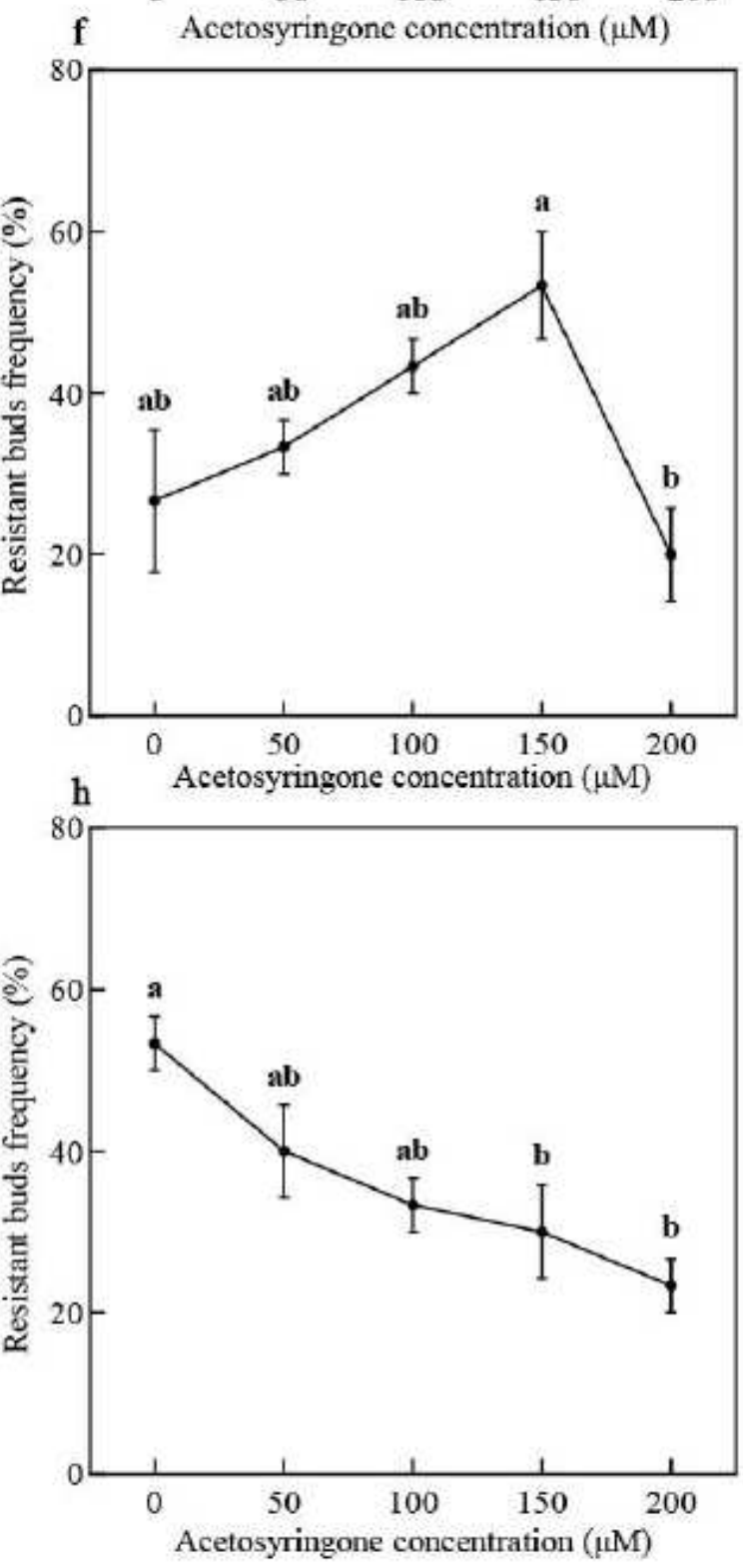

Figure 3 
Effect of acetosyringone on regeneration of resistant buds. a, Growth of explants in the per-cultivation stage with different concentrations of acetosyringone. b, Growth of explants in the infection stage with different concentrations of acetosyringone. $c$, Growth of explants in the co-cultivation stage with different concentrations of acetosyringone. $d$, Growth of explants in the selective culture stage with different concentrations of acetosyringone. Bar: $1 \mathrm{~cm}$. e, Analysis of variance of resistant buds frequency in the per-cultivation stage with different concentrations of acetosyringone. $f$, Analysis of variance of resistant buds frequency in the infection stage with different concentrations of acetosyringone. $g$, Analysis of variance of resistant buds frequency in the co-cultivation stage with different concentrations of acetosyringone. $h$, Analysis of variance of resistant buds frequency in the selective culture stage with different concentrations of acetosyringone. Values are means of 3 replicates \pm SE and 10 explants were repeated each time. Different lowercase letters show a significant difference at $p<0.05$ by Tukey's test after analysis of variance.

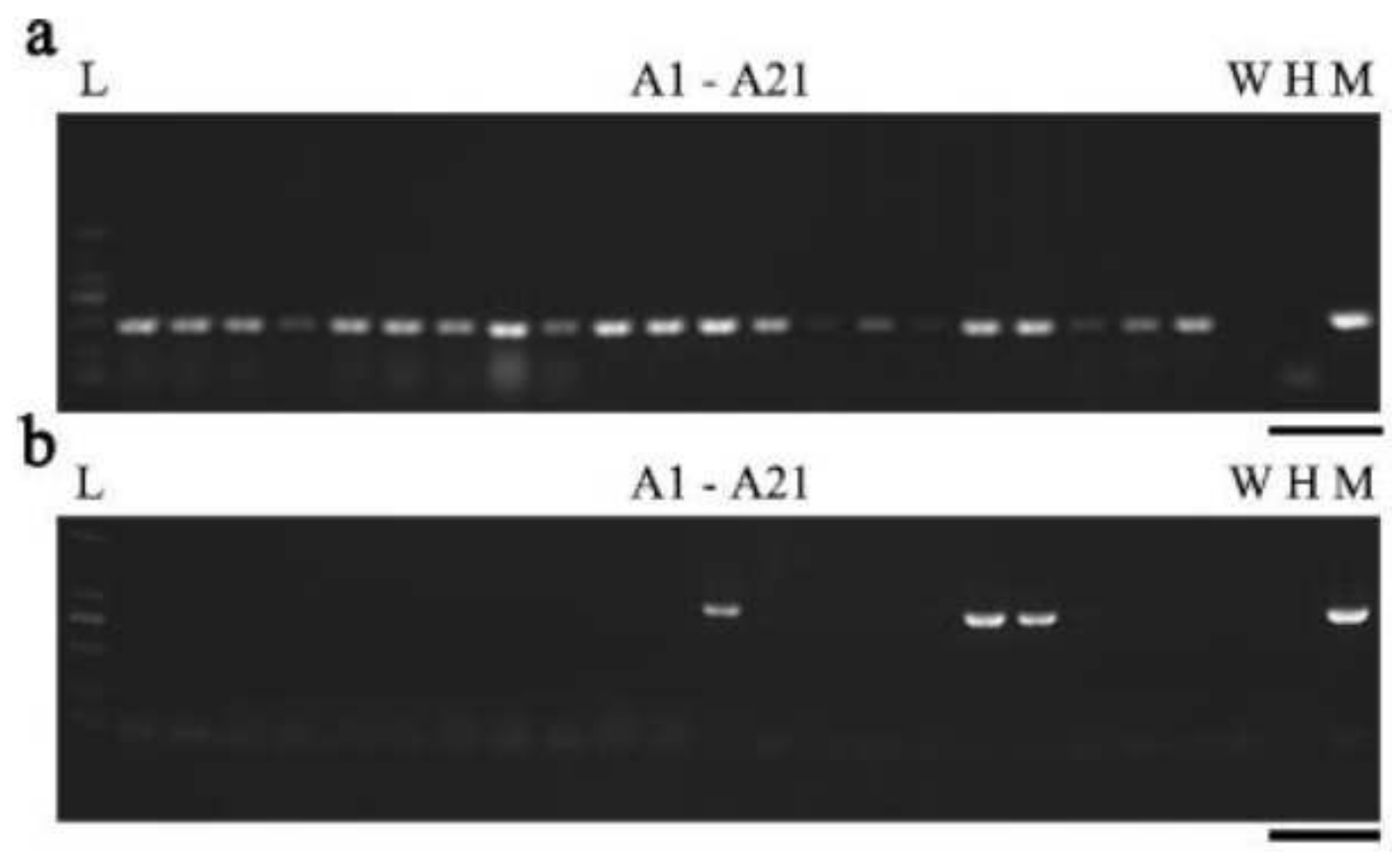

\section{Figure 4}

PCR products gel electrophoresis. a, Gel electrophoresis results of PCR products from npt II primers. b, Gel electrophoresis results of PCR products from HrcA primers. Lane $L$ is a line DNA marker of $2000 \mathrm{bp}$. Lane $A 1-A 21$ are different independently regenerated plants. Lane $W$ is a wide-type plant. Lane $H$ is without temple DNA (negative control). Lane M is a genomic DNA of positive Agrobacterium (positive control). Bar: $1 \mathrm{~cm}$. 


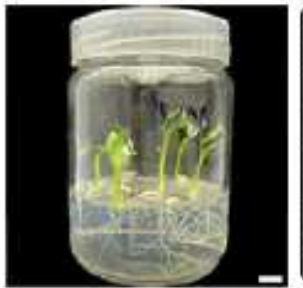

Step 1

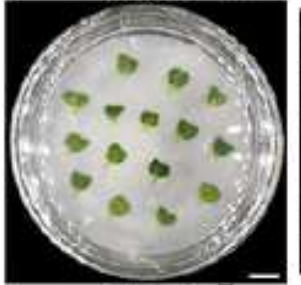

Seed disinfection:

$75 \%$ ethanol, $1 \mathrm{~min}$;

$15 \% \mathrm{NaClO}, 15 \mathrm{~min} ;$

sterile distilled water 4 times

Medium: medium-1

Condition: in the dark at $28^{\circ} \mathrm{C}$

for $48 \mathrm{~h}$ and light for $24 \mathrm{~h}$

Preparation of Agrobacterium suspension $\left(O D_{600}=0,6-0.8\right)$

Preparation of Agrobacterium inoculum $\left(O D_{f 00}=0.2-0.3\right)$

Medium: medium-III containing $150 \mu \mathrm{M}$ acetosyringone, shaking at $28^{\circ} \mathrm{C}$ for $1 \mathrm{~h}$

Vacuum system with the Agrobacterium inoculum, 0.094MPa for $5 \mathrm{~min}$

Co-culturation on filter paper wicks

Medium: medium-II containing $100 \mu \mathrm{M}$ acetosyringone

Condition: in the dark at $28^{\circ} \mathrm{C}$ for $48 \mathrm{~h}$

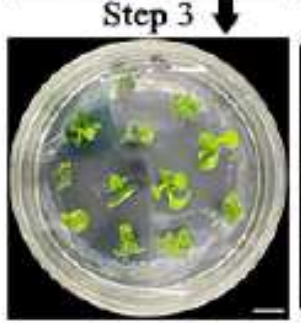

Washing the explants with sterilized distilled water, $5 \mathrm{~min} \times 5$

Selective culture 1

Medium: medium-II containing $25 \mathrm{mg} / \mathrm{L}$ kanamycin and $300 \mathrm{mg} / \mathrm{L}$ cefotaxime sodium

Condition: in the light at $28^{\circ} \mathrm{C}$ for $14 \mathrm{~d}$

Selective culture 2

Medium: medium-II containing $50 \mathrm{mg} / \mathrm{L}$ kanamycin and $300 \mathrm{mg} / \mathrm{L}$ cefotaxime sodium

Condition: in the light at $28^{\circ} \mathrm{C}$ for $14 \mathrm{~d}$

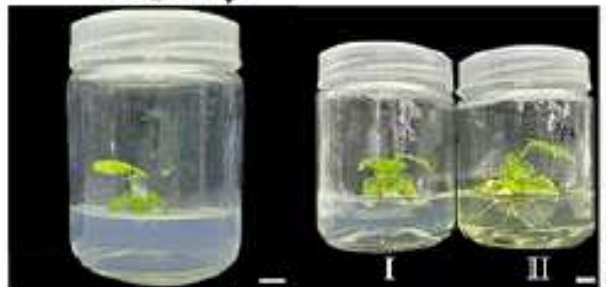

Cut off the resistant buds

53

Buds elongation culture

Medium: medium-IV containing $75 \mathrm{mg} / \mathrm{L}$ kanamycin and

$300 \mathrm{mg} / \mathrm{L}$ cefotaxime sodium

Condition: in the light at $28^{\circ} \mathrm{C}$ for $14 \mathrm{~d}$

Step 5

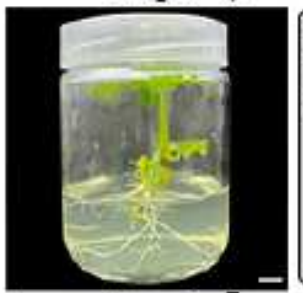

Rooting culture

Medium: medium- $V$ containing $100 \mathrm{mg} / \mathrm{L}$ kanamycin and $300 \mathrm{mg} / \mathrm{L}$ timentin

Condition: in the light at $28^{\circ} \mathrm{C}$ for $28 \mathrm{~d}$

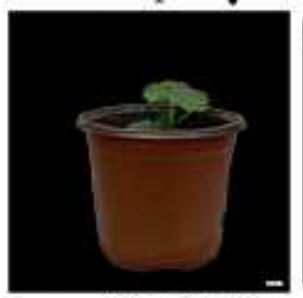

Step 7

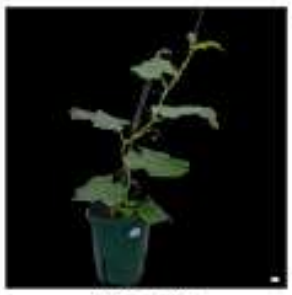

Step 8

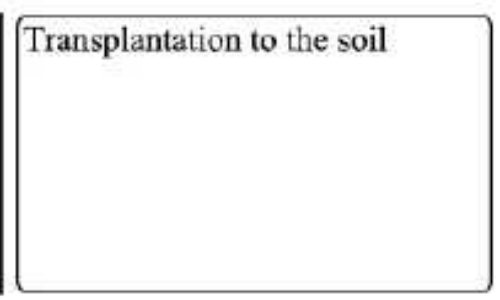

Figure 5

Steps in the transformation of cucumber 'Xintai mici' shoot organogenesis from cotyledonary nodes explants. Step 5-I, 300 mg/L timentin in culture medium as a bacteriostatic antibiotic. Step 5-II 300 mg/L cefotaxime sodium in culture medium as a bacteriostatic antibiotic. Bar: $1 \mathrm{~cm}$. 